\title{
Anemia and its association with Helicobacter pylori infection among adult dyspeptic patients attending Wachemo University Nigist Eleni Mohammad memorial Referral Hospital, Southwest Ethiopia
}

Kassahun Tassow Haile ( $\square$ kassahaile07@gmail.com )

Wolkite University

Deneke Wolde

Wachemo University

Girum Tesfaye

Jimma University

Tilahun Yemane

Jimma University

Abebe Timerga

Wolkite University

Admasu Haile

Wolkite University

Research article

Keywords: Anemia, H. pylori infection, dyspeptic, Hosanna, southwest, Ethiopia

Posted Date: March 18th, 2020

DOI: https://doi.org/10.21203/rs.3.rs-17878/v1

License: (c) (1) This work is licensed under a Creative Commons Attribution 4.0 International License.

Read Full License 


\section{Abstract}

Background: Anemia is a worldwide public health problem and also associated with H. pylori infection. Determining the association of anemia with $H$. pylori infection is important to develop evidence-based decision and intervention strategies. Association between anemia and $H$. pylori infection is not well known in Ethiopia. Thus, this study aimed to determine the association between anemia and H. pylori infection among adult dyspeptic patients attending Wachemo University Nigist Eleni Mohammad Memorial Referral Hospital in southwest Ethiopia.

Method: A cross-sectional study was conducted from January to April 2019 involving 362 consecutive adult dyspeptic patients who came to the hospital during the study period. Socio-demographic, clinical and other related data were collected by structured questionnaires. Four milliliters of the venous blood sample was collected for hematological parameters analysis and blood film preparation. A stool sample was collected to detect $H$. pylori antigen and intestinal parasites. Data were analyzed by SPSS version 21 . Logistic regression analyses were performed and $p$-value $<0.05$ was considered as statistically significant.

Results: The overall prevalence of anemia among dyspeptic patients was $24.3 \%$ (95\% Cl: 19.9- 28.7). Among H.pylori infected participants $29.2 \%$ were anemic, of which $69.2 \%$ had mild anemia and $63.5 \%$ had normocytic normochromic anemia. Rural residence (AOR: 1.9, 95\%Cl: 1.1-3.3), H. pylori infection (AOR: 1.77, 95\%Cl: 1.05-2.98) and intestinal parasitic infection (AOR: $2.14,95 \% \mathrm{Cl}: 1.14-4.03$ ) were significantly associated with anemia.

Conclusion: The prevalence of anemia in this study indicated that it is a moderate public health problem. Rural residence, $H$. pylori and intestinal parasitic infection were significantly associated with anemia. The findings of this study should be taken into account for the prevention and control of anemia among dyspeptic adults.

\section{Background}

Anemia is a global public health problem affecting both developed and developing countries [1]. A study reported a $32.9 \%$ global burden of anemia in all ages combined, Sub-Saharan Africa shared the highestburden [2]. It has serious implications for health, as well as social and economic development [3]. It increases susceptibility to infections, impairs the physical capacity and work performance of the adults $[4,5]$. It is a significant public health problem in Ethiopia, according to a national report of $2016,24 \%$ of women and $15 \%$ of men were anemic [6].

Identifying possible contributing factors of anemia at different setups is important to combat its burden and for proper management of anemic patients. Several studies identified different factors associated with anemia among adults [7-9]. Recently Helicobacter pylori (H. pylori) infection has been implicated in some of the hematological manifestations like anemia, iron and vitamin B12 deficiency [10-12]. 
H. pylori infection is associated with anemia by impairing iron absorption as a result of chronic gastritis which causes gastric hypochlorhydria, leading to impair reduction of the dietary iron from the ferric to ferrous form $[13,14]$. Because most dietary iron is in the ferric form, and an acidic intragastric $\mathrm{pH}$ and ascorbic acid are needed to reduce it to the ferrous form for absorption [15]. Hence, H. pylori is a major cause of chronic superficial gastritis leading to atrophy of gastric glands, resulting in reducing gastric acid secretion[16].

H. pylori uptakes iron for their growth by competing with their host [4], and increased hepcidin production secondary to $\mathrm{H}$. pylori infection decreases the release of iron from macrophages and entrecote [17].

Because hepcidin, act as an acute-phase reactant in response to the inflammation produced in the gastric mucosa, resulting in anemia of inflammation or chronic disease [14]. Other possible mechanism includes iron loss via hemorrhagic gastritis and active bleeding peptic ulcers [18].

$\mathrm{H}$. pylori infection is a prevalent microbial infection around the world, $48.6 \%$ of the adult population were affected globally [19]. It has been found more frequently in dyspeptic patients, studies reported $71 \%$, 72.2\% and 83.3\% in Somali [20], Southern [21] and Northern Ethiopia [22], respectively.

In Ethiopia data regarding the association of H.pylori infection with anemia among adults is scarce, despite a high prevalence of this infection [20-23]. Therefore disclosing the association of H. pylori infection with anemia among adult dyspeptic patients will help to develop evidence-based decision and intervention strategies. The availability of updated data on the magnitude, type, and severity of anemia has a major role in the management of anemic patients. Therefore, this study aimed to determine the prevalence, type, and severity of anemia and its association with $\mathrm{H}$. pylori infection among adult dyspeptic patients in Southwest Ethiopia.

\section{Methods}

\section{Methods}

\section{Study area}

This study was conducted at Wachemo University Nigist Eleni Mohammed Memorial Referral Hospital (WUNEMMRH). The hospital is located in Hosanna town, Hadiya Zone, Southern Nations Nationalities, and People's Regional state, southwest Ethiopia. The twon is $232 \mathrm{~km}$ far from capital-city, Addis Ababa and lies in on average at 2,177 meters above sea level. The hospital gives health services for peoples living in the Hadiya zone and surrounding districts. Its catchment area population estimated around 3.2 million.

\section{Study design and period}

The facility-based cross-sectional study design was conducted among adults from January 2019 to April 2019. 


\section{Sample size and sampling technique}

The sample size was determined by using a single population proportion formula considering a $95 \%$ confidence interval $(\mathrm{Cl})$, a $5 \%$ margin of error and a $30.9 \%$ prevalence of anemia [24]. After adding (10\%) non-response rate we got the final sample size of 362. All consecutively identified adult patients (age $\geq 18$ years) who have dyspeptic complaints were included in the study until attaining sample size. Patients who took treatment for $H$. pylori infection within last three month [25], who had previous stomach or small bowel surgery, donate blood within last three month and on treatment for anemia before data collection, pregnant women and severally ill patients thus unable to respond to the questionnaire were excluded.

\section{Data collection and laborator procedure}

Data on socio-demographic characteristics, clinical and other related factors were collected using a structured questionnaire by trained nurses. For laboratory data, $4 \mathrm{ml}$ of the venous blood sample was collected in ethylenediaminetetraacetic acid (EDTA) tubes by laboratory technologists from each study participant for hematological parameter analysis and blood film preparation. Hematological parameters were determined using automated blood analyzer Mindray BC-3000 plus (Shenzhen Mindray Bio-Medical Electronics, China).

Anemia was defined according to the World health organization (WHO) cutoff value as an HGB concentration $<12 \mathrm{~g} / \mathrm{dl}$ in women and $<13 \mathrm{~g} / \mathrm{dl}$ in men. It is categorized as mild (HGB,11-11.9 g/dl in women and $11-12.9 \mathrm{~g} / \mathrm{dl}$ in men), moderate (HGB, 8-10.9 g/dl in both men and women), and severe anemia (HGB, $<8 \mathrm{~g} / \mathrm{dl}$ in both men and women) [26]. It can be classified as microcytic (MCV, $<80 \mathrm{fl}$ ), normocytic (MCV , $80 \mathrm{fl}-100 \mathrm{fl}$ ) and macrocytic (MCV, >100 fl) [27,28]. Thin blood films were prepared, airdried, labeled and then stained by Wrights stain to evaluate RBC morphology of anemic study participants.

Also, after explaining how to collect representative stool specimen clean cupped plastic container was given to the participants. Approximately five gram of stool specimen was collected from each study participant and checked for the presence of $H$. pylori antigen by wondfo one step $H$. pylori feces test (Guangzhou Wondfo Biotech, China) and intestinal parasites were detected by saline wet mount techniques. Anthropometric measurements (height and weight) were measured from all study participants and body mass index (BMI) was computed as weight in kilogram divided by the square of height in meter and categorized in a four groups; $\mathrm{BMK}<18.5 \mathrm{~kg} / \mathrm{m}^{2}$ as underweight, $\mathrm{BMI}=18.5-24.9$ $\mathrm{kg} / \mathrm{m}^{2}$ as normal weight, $\mathrm{BMI}=25-29.9 \mathrm{~kg} / \mathrm{m}^{2}$ as overweight, and $\mathrm{BMI} \geq 30 \mathrm{~kg} / \mathrm{m}^{2}$ as obese [29].

To ensure the quality of data, training was given to data collectors, completeness of each questionnaire was checked regularly, reagents and test kits were checked for their expiry date. All laboratory tests were done by following the standard operating procedures (SOPs) and manufacturer instructions.

\section{Data analysis and interpretation}


Data were entered and analyzed by using SPSS version 21 (SPSS, Chicago, IL, USA). Frequency tables and descriptive summaries were used to describe the study variables. Association between anemia and H. pylori infection was assessed by logistic regression. Bivariate analysis was performed for each independent variable to select candidate's variables for multivariate analysis. Variables in bivariate analysis with P-value $<0.25$ were taken as candidates for multivariate analysis. Multiple logistic regression analysis was used to identify associated risk factors for the prevalence of anemia. P-value was set at $<0.05$ for statistical significance.

\section{Results}

\section{Socio-demographic, clinical and related characteristics of the study participants}

A total of 362 adult dyspeptic patients, $58 \%$ females and $42 \%$ males were included in this study age ranging from 18 to 49 years, with a mean $( \pm S D)$ age of $31.1( \pm 7.5)$ years. The majority of them were rural area residents $57.7 \%$ and married $60.2 \%$. H. pylori infection and intestinal parasites were detected in $49.2 \%$ and $16.3 \%$ of the study participants, respectively. Among the study participants, $2.5 \%$ had chronic disease and $3 \%$ had a history of bleedings. The majority of $61.6 \%$ of participants had a habit of consumption of fruit and vegetable during the time of the data collection [Table1].

\section{Prevalence, severity, and types of anemia among study participants}

The mean ( $( \pm S D)$ HGB concentration of the study participants was $13.5(1.93) \mathrm{g} / \mathrm{dl}$ in females and $14.1(1.55) \mathrm{g} / \mathrm{dl}$ in males. The overall prevalence of anemia among dyspeptic patients was $24.3 \%$ with $95 \% \mathrm{Cl}$ (19.9-28.7). Of which $71.6 \%$ had mild and $28.4 \%$ moderate anemia but there was no severe anemia identified. Out of anemic participants, $27.3 \%, 5 \%$, and $2.3 \%$ had microcytic, normocytic and macrocytic types of anemia, respectively.

\section{Prevalence, severity, types, and association of anemia with $H$. pylori infection}

The prevalence of anemia among H.pylori infected participants was $29.2 \%$, of which $69.2 \%, 30.8 \%$ had mild and moderate anemia, respectively. Among H.pylori infected study participants, $34.6 \%, 63.5 \%$, and $1.9 \%$ had microcytic, normocytic and macrocytic anemia, respectively.

After adjusting for other variables, $H$. pylori infection showed a statistically significant association with anemia [Table 2].

\section{Factors associated with anemia among study participants}

After adjusting for other variables: rural residence (AOR: 1.9, 95\%Cl: 1.1-3.3), H. pylori infection (AOR: 1.77, 95\% Cl: 1.05-2.98) and intestinal parasitic infection (AOR: $2.14,95 \% \mathrm{Cl}: 1.14-4.03$ ) were significantly associated factors with anemia among study participants [Table 2].

\section{Discussion}


The current study attempted to asses anemia prevalence and its association with $H$. pylori infection among adult dyspeptic patients. The overall prevalence of anemia among adult dyspeptic patients was $24.3 \%$. According to the WHO classification of the public health importance of anemia [26], anemia prevalence in this study indicated a moderate public health problem.

The overall prevalence of anemia obtained in this study was consistent with a study done in Butajira, Ethiopia (26.9\%) [24], Cuba (24.6\%) [30], Karachi (25.2\%) [31] and Southern Brazil 20.6\% [32]. However, the findings of this study were lower than reports from Kutahya, Turkey (53.2\%) [33] and Central Plateau (63.6\%) [34]. The lower prevalence of anemia in the current study might be due to differences in cutoff values of HGB to define anemia and difference in sample size. For example, in Kutahya, Turkey cutoff values of HGB to define anemia for male was less than $14 \mathrm{~g} / \mathrm{dl}$ which is different as compared to our study (less than $13 \mathrm{~g} / \mathrm{dl}$ for male).

The current study finding revealed a higher prevalence of anemia compared to studies conducted in China (5.3\%) [35]. This might be due to methodological variation and the presence of intestinal parasitic infection in our study (16.3\%). For instance, a study conducted in China was retrospective and exclude study participants without results of either $H$. pylori infection status or hematological parameter.

The prevalence of anemia among H.pylori infected participants obtained in this study was $29.2 \%$, which was consistent with the study finding in Butajira, Ethiopia $30.9 \%$ [24], while higher magnitudes of anemia among H.pylori infected were reported from Kutahya, Turkey (91.8\%) [33] and Central Plateau (55.2\%) [34].

According to WHO classification for the degree of anemia based on HGB concentration [26], in this study, mild anemia was common (69.2\%) followed by moderate anemia (30.8\%) among H.pylori infected study participants. Similar findings were reported in studies done in China [35] and Cuba [30].

Considering the morphological classification of anemia, normocytic-normochromic anemia (63.5\%) was the predominant type of anemia among H.pylori infected study participants followed by microcytic hypochromic anemia (34.6\%) in this study. This might be due to the reason that blood loss secondary to chronic erosive gastritis, decreased iron absorption secondary to chronic gastritis and hypochlorhydria, and also rises in hepcidin level after $H$. pylori infection which might contribute in anemia $[11,14]$.

The association between anemia and $H$. pylori infection has been explored by the number of previous studies $[24,30,32-35]$. The current study revealed that there is a statistically significant association between anemia and $H$. pylori infection. $H$. pylori-infected individuals were 1.77 times more likely to be anemic compared to their non-infected counterparts. These findings were in agreement with previous studies conducted in China [35,47] and the USA [37]. Also, different studies had reported similar findings $[10,38-40]$.

The possible mechanism that might explain the association between anemia and $H$. pylori infection may include; consumption of iron by the organism itself [41], gastrointestinal blood loss due to H. pylori- 
induced gastrointestinal lesions [14], and gastritis increased levels of neutrophil-derived lactoferrin, and since H. pylori has a lactoferrin-binding protein receptor, the infection may result in increased iron losses related to bacterial turnover. Since these bacteria have a high turnover rate, a large amount of iron may be lost in stools in the form of dead bacteria [11,42]. Also, H. pylori chronic gastritis can change the physiology of the stomach, inducing reductions in gastric acid secretion, while acidic intragastric $\mathrm{PH}$ was essential for the absorption of dietary iron; thereby inhibiting dietary iron absorption[12].

Gastrointestinal blood loss is one of the most important underlying causes of anemia in adults $[45,46]$. In this study, anemia was significantly associated with intestinal parasitic infection. Study participants who had intestinal parasitic infection were 2.14 times more likely to be anemic compared to their non-infected counterparts. A similar observation was reported from Uganda [8] and India [9]. This might be due to gastrointestinal blood loss which may contribute to anemia. The worm in the intestine may cause blood loss as a result of the attachment to the intestinal mucosa and chronic infections may lead to iron deficiency and anemia resulting from the excessive loss of iron $[45,47]$.

Socio-demographic factors can play role in determining anemia [7]. In the current study, anemia was significantly associated with rural residence. This finding is in agreement with the study done in India [48]. This might be likely related to a lack of information about adequate nutrition and inaccessibility of health care centers. Thus, they lack information on the causes of anemia and possible prevention strategies to risk factors of anemia. The limitation of this study was, micronutrient (serum iron, foliate and vitamin-B12) levels were not assessed and intestinal parasites were not detected by concentration techniques due to logistic constraints. The cross-sectional nature of the study design prohibited to establish causal links between anemia and factors which are significantly associated with anemia.

\section{Conclusion}

The prevalence of anemia in this study indicated that it is a moderate public health problem. A higher prevalence of anemia was observed in study participants having intestinal parasitic infection, H. pylori infection and resides in a rural area. Rural residence, $H$. pylori and intestinal parasitic infection were significantly associated with anemia. The findings of this study should be taken into account for developing intervention-based strategies on identified factors mainly on; prevention and control of $\mathrm{H}$. pylori and intestinal parasitic infection. Routine screening and treatments of $H$. pylori and intestinal parasitic infection among dyspeptic adults, and performing large community-based studies are recommended.

\section{Abbreviations}

AOR: Adjusted Odds Ratio; BMI: Body mass index; COR: Crude Odds Ratio; EDTA:

Ethylenediaminetetraacetic acid; H. pylori: Helicobacter pylori; HGB: Hemoglobin; MCV: Mean cell volume; SOPs: Standard operating procedures; WHO: World Health Origination; WUNEMMRH: Wachemo University Nigist Eleni Mohammed Memorial Referral Hospital. 


\section{Declarations}

\section{Ethics approval and consent to participate}

Ethical clearance was obtained from Jimma University Ethical Review Board. A letter of cooperation was written to WUNEMMRH and permission was obtained from the hospital administration. Written informed consent was obtained from each study participant after explaining the purpose and procedures of the study.

The study participant results were kept confidential and they were assured that only aggregate data will be reported. All necessary results of the participant were communicated with the physician for proper management.

\section{Consent for publication}

Not applicable.

\section{Availability of data and materials}

The original data for this study is available from the corresponding author on a reasonable request.

\section{Competing interest}

The authors declared that they have no competing interests.

\section{Funding}

The study was sponsored by Jimma University. The funder had no role in the study design, collection, analysis, and interpretation of data and in writing the manuscript.

\section{Authors' contributions}

DW, AT, AH, study designing, data collection, entry, and cleaning; KH designed the study, data collection, data cleaning, data analysis, interpretation and wrote the manuscript; GT, TY assisted in the study design, data collection, entry, cleaning and data analysis. All authors read and approved the final manuscript.

\section{Acknowledgments}

We would like to acknowledge study participants who were volunteers to give all relevant information for the study. We are grateful to WUNEMMRH staff members for their support during the data collection. This study was finically supported by Jimma University.

\section{References}


1. Brunode B, Erin M, Marry C. Worldwide prevalence of anaemia 1993-2005:World Health organzation;Geneva, Switzerland. 2008.

2. Kassebaum NJ, Jasrasaria R, Naghavi M, Wulf SK, Johns N, Lozano R, et al. a systematic analysis of global anemia burden from 1990 to 2010. Blood. 2014;123(5):615-25.

3. Pasricha S, Drakesmith H, Black J, Hipgrave D, Biggs B. Control of iron deficiency anemia in low- and middle-income countries. Am Soc hematiology. 2013;121(14):1-3.

4. Kumar V, Choudhry VP. Iron Deficiency and Infection. Indian J Pediatr. 2010;77:789-93.

5. Lopez A, Cacoub P, Macdougall IC, Peyrin-biroulet L. Iron deficiency anaemia. Lancet. 2015;6736(15):1-10.

6. Ethiopia Central Statistical Agency and ICF. Ethiopia Demographic health Survey 2016. 2016.

7. Imaad MI, Azeez K, Alwin A, Sobhith VK. Role of socio-demographic and cultural factors on anemia in a tribal population of North Kerala, India. Int J Community Med Public Heal. 2016;3(5):1183-8.

8. Mugisha JO, Baisley K, Asiki G, Seeley J, Kuper H. Prevalence, Types , Risk Factors and Clinical Correlates of Anaemia in Older People in a Rural Ugandan Population. PLoS One. 2013;8(10):1-10.

9. Srinivas V, Mankeshwar R. Prevalence and determinants of nutritional anemia in an urban area among unmarried adolescent girls. Int J Med Public Heal. 2015;5(4):283-8.

10. Hudak L, Jaraisy A, Haj S, Muhsen K. An updated systematic review and meta-analysis on the association between Helicobacter pylori infection and iron deficiency anemia. Wiley. 2017;1-16.

11. Tsay F, Hsu P. H . pylori infection and extra-gastroduodenal diseases. J Biomed Sci. 2018;1-8.

12. Gravina AG, Zagari RM, De Musis C, Romano L, Loguercio C, Romano M. Helicobacter pylori and extragastric diseases: A review. World J gasteroenterology. 2018;24(29):3204-21.

13. Andrea L, Carol A, Jason A, John S. Is achlorhydria a cause of iron deficiency anemia? Am J Clin Nutr. 2015;102:9-19.

14.Campuzano-maya G. Helicobacter pylori and Hematologic Diseases. World J gasteroenterology. 2016;33-9.

15. Annibale B, Capurso G, Lahner E, Passi E, Ricci R, Maggio F, Dellefave G. Concomitant alterations in intragastric $\mathrm{pH}$ and ascorbic acid concentration in patients with Helicobacter pylori gastritis and associated iron deficiency anaemia. Gut. 2003;52:496-501.

16. Waldum HL, Kleveland PM, Sordaloystein F. Helicobacter pylori and gastric acid. Therap Adv Gastroenterol. 2016;9(6):836-44.

17. Augusto J, Díaz U, Regino WO, Zuleta MG. Helicobacter pylori and hematologic diseases. World J gasteroenterology. 2013;28(4):323-31.

18. Tan H, Goh K. Extragastrointestinal manifestations of Helicobacter pylori infection: Facts or myth? J Dig Dis. 2012;13:342-9.

19. Zamani M, Ebrahimtabar F, Zamani V, Miller WH, Alizadeh-Navaei R, Shokri-Shirvani J, et al. the worldwide prevalence of Helicobacter pylori infection. Aliment Pharmacol Ther. 2018;868-76. 
20. Alebie G. Prevalence of Helicobacter Pylori Infection and Associated Factors among Gastritis Students in Jigjiga University , Jigjiga, Somali Regional State of Ethiopia. J Bacteriol Mycol. 2016;3(3):1-7.

21. Tadesse E, Daka D, Yemane D, Shimelis T. Seroprevalence of Helicobacter pylori infection and its related risk factors in symptomatic patients in southern Ethiopia. BMC Res Notes. 2014;7(1):1-5.

22. Abebaw W, Kibret M, Abera B. Prevalence and Risk Factors of H . pylori from Dyspeptic Patients in Northwest Ethiopia. Asian Pacific J Cancer Prev. 2014;15:4459-63.

23. Dilnessa T, Amentie M. Prevalence of Helicobacter pylori and risk factors among dyspepsia and nondyspepsia adults at Assosa General Hospital , West Ethiopia. Ethiop J Heal Dev. 2017;31(1).

24. Kibru D, Gelaw B, Alemu A, Addis Z. Helicobacter pylori infection and its association with anemia among adult dyspeptic patients attending Butajira Hospital , Ethiopia. BMC Infect Dis. 2014;14:1-7.

25. Kalali B, Formichella L, Gerhard M. Diagnosis of Helicobacter pylori: Changes towards the Future. open acess Dis. 2015;3:122-35.

26. World health organazation. Haemoglobin concentrations for the diagnosis of anaemia and assessment of severity. Vitamin and Mineral Nutrition Information System. Geneva, World Health Organization,2011.

27. Antonio J, Chulilla M, Soledad M, Colás R, Martín MG. Classification of anemia for gastroenterologists. World J gasteroenterology. 2009;15(37):4627-37.

28. Patidar E. red blood cell morphology : still an important toolfor anemia typing. Int J Res Granthaalayah. 2018;6(3):298-301.

29. Center of disease control(CDC). Body Mass Index: Considerations for Practitioners. 2010.

30. Gisela M, Beatriz BT, María Elena DS, Ana María GA, Derbis CH, Caridad AO et al.Anemia and Iron Deficiency Related to Inflammation, Helicobacter pylori Infection and Adiposity in Reproductive-age Cuban Women. MEDICC. 2017;19(2):10-7.

31. Abdul G, Gordhan S, NandLal S. frequency of anemia in patients wih Helicibacter pylori infection presenting to teritiary care hospital. Am J Pharm Sci. 2017;4(11):3874-8.

32. Iná SS, Gicele CM, Neiva CJ, Giovana CT, José B, Domingo AB, et al. Helicobacter pylori and anemia: a community-based cross-sectional study among adults in Southern Brazil. Cad Saúde Pública. 2009;25(12):2653-60.

33. Mustafa CA, Erim G, Zulfu B, Sezgin Z, Sukru AD, Emel K et al. Correlation of anemia and Helicobacter pylori infection among dyspeptic patients in Kutahya region. Eur J Med Sci. 2015;2(1):1-5.

34. Shak JR, Sodikoff JB, Speckman RA, Rollin FG, Chery MP, Cole CR, et al. Anemia and Helicobacter pylori seroreactivity in a Rural Haitian population. Am J Trop Med Hyg. 2011;85(5):913-8.

35. Xu M, Cao B, Yuan B, Yin J, Liu L, Lu Q. Association of anaemia with Helicobacter pylori infection. Sci Rep. 2017;1-7. 
36. Hou B, Zhang M, Liu M, Dai W, Lin Y, Li Y, et al. Association of active Helicobacter pylori infection and anemia in elderly males. BMC Infect Dis. 2019;19(228):1-9.

37. Cardenas VM, Mulla ZD, Ortiz M, Graham DY. Iron Deficiency and Helicobacter pylori Infection in the United States. Am J Epidemiol. 2006;163(2):127-34.

38. Qu X, Huang X, Xiong P, Zhu C, Huang Y, Lu L, et al. Does Helicobacter pylori infection play a role in iron deficiency anemia? A meta-analysis. World J gasteroenterology. 2010;16(7):886-96.

39. Monzón H, Esteve M, Rosinach M, Loras C, Espinós JC, Viver JM, et al. Helicobacter pylori infection as a cause of iron deficiency anaemia of unknown origin. World $\mathrm{J}$ gasteroenterology. 2013;19(26):4166-71.

40. Huang X, Qu X, Yan W, Huang Y, Cai M, Hu B, et al. Iron deficiency anaemia can be improved after eradication of Helicobacter pylori. Postgr Med J. 2010;86:272-8.

41. Bianca DR, Francesco G. Helicobacter pylori and extragastric diseases. John Wiley. 2018;23:1-7.

42. Campuzano maya G. Hematologic manifestations of Helicobacter pylori infection. World $J$ gasteroenterology. 2014;20(36):12818-38.

43. Bashir F, Nageen A, Kidwai SS, Zulfikar S, Shiraz S, Ara J. Anemia in Hospitalized Patient: Prevalence , Etiology and Risk Factors. J Liaquat Uni Med Heal Sci. 2017;16(2):80-5.

44. Pasricha SS, Flecknoe-brown SC, Allen KJ, Gibson PR, Mcmahon LP, Olynyk JK, et al. Diagnosis and management of iron deficiency anaemia: a clinical update. MJA. 2010;193(9):525-32.

45. Shaw JG, Friedman JF. Iron Deficiency Anemia: Focus on Infectious Diseases in Lesser Developed Countries. Hindaw Publ Corp BioMed Res Int. 2011;2011:1-11.

46. Little M, Zivot C, Humphries S, Dodd W, Patel K, Dewey C. Burden and Determinants of Anemia in South India. Hindaw Publ Corp BioMed Res Int. 2018;1-10.

\section{Tables}

\section{Table 1 Baseline characteristics of study participants}




\begin{tabular}{|c|c|}
\hline Characteristics & Frequency (\%) \\
\hline \multicolumn{2}{|l|}{ Age in years } \\
\hline $18-24$ & $85(23.5)$ \\
\hline $25-29$ & $91(25.1)$ \\
\hline $30-34$ & $59(16.3)$ \\
\hline $35-39$ & $56(15.5)$ \\
\hline $40-44$ & $54(14.9)$ \\
\hline $45-49$ & $17(4.7)$ \\
\hline \multicolumn{2}{|l|}{ Gender } \\
\hline Female & $210(58)$ \\
\hline Male & $152(42)$ \\
\hline \multicolumn{2}{|l|}{ Residence } \\
\hline Urban & $153(42.3)$ \\
\hline Rural & $209(57.7)$ \\
\hline \multicolumn{2}{|l|}{ Marital status } \\
\hline Single & 136(37.6) \\
\hline Married & $218(60.2)$ \\
\hline Divorced & $4(1.1)$ \\
\hline Widowed & $4(1.1)$ \\
\hline \multicolumn{2}{|c|}{ Educational status } \\
\hline Illiterate & $99(27.3)$ \\
\hline Primary & $50(13.8)$ \\
\hline Secondary & $115(31.8)$ \\
\hline Higher & $98(27.1)$ \\
\hline \multicolumn{2}{|c|}{ Monthly income in Ethiopian birr } \\
\hline$<776$ & $69(19.1)$ \\
\hline 776-1552 & $97(26.8)$ \\
\hline$>1552$ & $196(54.1)$ \\
\hline \multicolumn{2}{|c|}{ Occupational status } \\
\hline Farmer & $94(26)$ \\
\hline Daily laborer & $55(15.2)$ \\
\hline Employee & $80(22.1)$ \\
\hline Students & $69(19.1)$ \\
\hline Merchants & $57(15.7)$ \\
\hline Self employee & $7(1.9)$ \\
\hline \multicolumn{2}{|c|}{ Intestinal parasite } \\
\hline Positive & $59(16.3)$ \\
\hline Negative & $303(83.7)$ \\
\hline \multicolumn{2}{|l|}{ Chronic disease } \\
\hline Yes & $9(2.5)$ \\
\hline No & $353(97.5)$ \\
\hline \multicolumn{2}{|c|}{ History of bleedings } \\
\hline Yes & $11(3)$ \\
\hline No & $351(97)$ \\
\hline \multicolumn{2}{|l|}{$\mathrm{BMI}$ in $\mathrm{kg} / \mathrm{m}^{2}$} \\
\hline Underweight & $11(3)$ \\
\hline Normal weight & $303(83.7)$ \\
\hline Overweight & $48(13.3)$ \\
\hline Underweight & $11(3)$ \\
\hline \multicolumn{2}{|c|}{ Fruit/vegetable consumption } \\
\hline Yes & $223(61.6)$ \\
\hline No & $139(38.4)$ \\
\hline
\end{tabular}


Red meat consumption

Yes 123(34)

No 239(66)

Table 2 Factors associated with anemia among study participants 


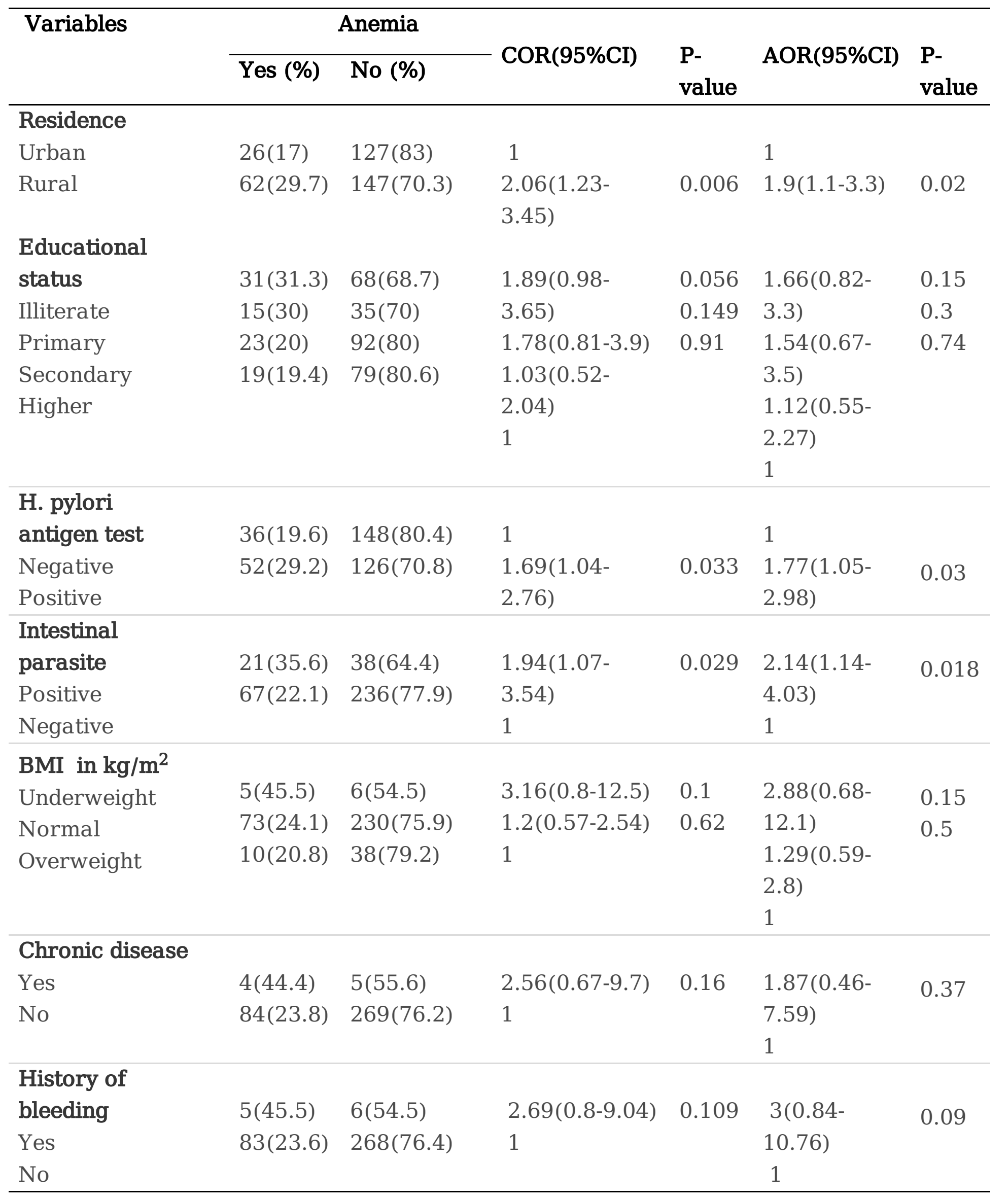

